\title{
The science foundation for the establishment of cooperation mechanism on trans-boundary water management
}

\author{
Hung V. Bui ${ }^{1 *}$, \& Diep N. Nguyen ${ }^{2}$ \\ ${ }^{1}$ Department of Environmental Management, University of Science, Ho Chi Minh City, Vietnam \\ ${ }^{2}$ Department of Political Theory, University of Labour and Social Affairs, Ho Chi Minh City, Vietnam
}

ARTICLE INFO
Research paper
Received: April 02, 2018
Revised: May 29, 2018
Accepted: June 17, 2018
Keywords
Cooperation mechanism
Mekong Delta
Mekong River Commission
National Mekong Committee
Trans-boundary water management
*Corresponding author

Bui Viet Hung

Email: bvhung@hcmus.edu.vn

\begin{abstract}
The Mekong Delta (MD) is of socio-economic importance for both Vietnam and Cambodia. The trans-boundary dimension and respective management issues are highly relevant for the economic development and security of each country. Because the economic development of each country is different in the boundary region of $\mathrm{MD}$, there are many kinds of natural hazard occurred in MD (including flood, drought, acid sulphate soils, and saltwater intrusion), the impact of upstream development, a myriad of flood controlling infrastructure, and the implications of climate change. To resolve these above problems and maintain the boundary security condition, the two countries are implementing many cooperation and coordination mechanisms $(\mathrm{CMs})$ at central and provincial levels. In this article, the current CMs between the two countries are presented to clarify the implementing status, effective and coherent level of the trans-boundary water management (TWM). From that, some recommendations will be proposed to set up a new CM closed with TWM for the boundary provinces in MD.
\end{abstract}

Cited as: Bui, H. V., \& Nguyen, D. N. (2018). The science foundation for the establishment of cooperation mechanism on trans-boundary water management. The Journal of Agriculture and Development 17(3), 61-68.

\section{Introduction}

The Mekong Delta extends from central Cambodia to Vietnam, where the Mekong River empties into the sea. As the "rice bowl" of both countries, the delta is essential for their food security and income. However, the upstream hydropower development and delta's flood controlling infrastructures affect fisheries, the floodplains, sediment movement, and water quality. Impacts of climate change, including severe floods and droughts and saltwater intrusion, also threaten the delta's natural resources (MRC, 2017).

Due to the need for economic development, security as well as the mitigation of adverse impacts at the border areas of Vietnam and Cambodia, the Governments of the two countries as well as the border provinces' administrations have carried out many institutional activities to promote a cooperation and dialogue. The most raised problems at present are the issues related directly or indirectly to water in Mekong River and they still not have a solution or still not have solved to cause many misunderstanding and complex for each other. To better manage the shared resources in the Mekong Delta, Cambodia and Vietnam work together to develop joint planning and harmonised mechanisms for the management of water resources through a bilateral project supported by the Mekong River Commission (MRC). After consultations with government officials and local stakeholders and field surveys, the two countries have identified six main issues to address in cooperation. Details of the six main 
issues are recorded in the joint technical paper, Trans-boundary Water Management Issues in the Mekong Delta of Cambodia and Vietnam, published in September 2017 (MRC, 2017).

The six joint issues on TWM between Vietnam and Cambodia are:

- Flood and drought strategic planning.

- Infrastructure development and investment.

- Coordination and Communication Mechanisms.

- Human and institutional capacity building at the managerial and technical level.

- Environmental, social and economic impacts of development and climate change.

- The implementation of the Navigation Agreement between Cambodia and Vietnam.

Therefore, for the solution all above issues, it should review the institute content of current cooperation and dialogue mechanism between two countries. Based on the analysis, to propose the $\mathrm{CM}$ on the TWM, which will aims to improve and enforce the quality of existing coordination and cooperation mechanisms and to focus on the boundary provincial level in MD's boundary region.

\section{Advantages and Disadvantages on The Implementation Existing CMs Among Vietnam and Cambodia}

At present, the trans-boundary cooperation and dialogue mechanisms between Vietnam and Cambodia are established at two levels, which are the central and boundary provincial levels. They are:

- The CMs at the national level: The central coordination and cooperation mechanisms are based on many agreements, treaties or memorandum of understanding. These documents are included as (Bui, 2015):

$\diamond$ The Treaty of Peace, Friendship and Cooperation between the Socialist Republic of Vietnam and the People's Republic of Cambodia signed on February 18, 1979. The main content of the treaty laid the foundation for peace and cooperation between the two neighboring countries.

$\diamond$ The Agreement on the Historical Waters of the Socialist Republic of Vietnam and the People's Republic of Cambodia signed on July 7, 1982, delineates the boundaries of coastal and marine waters belonging to the two countries. $\diamond$ The Agreement on the principle of resolving the Vietnam-Cambodia border issue (signed on July 20, 1983).

$\diamond$ The 1995 Agreement on Mekong River low basin's cooperation in sustainable development between the Governments of the Kingdom of Cambodia, the Lao People's Democratic Republic, the Socialist Republic of Vietnam and the Kingdom of Thailand.

$\diamond$ The Agreement on Water transport on the Mekong River and Transit at the common boundary region between Vietnam and Cambodia, signed on 17 December 2009.

$\diamond$ The Memorandum of Understanding (MoU) between the Governments of the Kingdom of Cambodia, the Lao People's Democratic Republic and the Socialist Republic of Vietnam for Road Transport signed on 17 January 2013. The Memorandum of Understanding favorable transportation of goods and people between the participations; cooperate in socio-economic development and bring stability for each country.

- The CMs at the bordering provincial levels: The boundary local $\mathrm{CMs}$ are based on many agreements, memorandum of understanding. These documents are included as (Bui, 2015):

$\diamond$ The Agreement on activities at border water region between provinces of Kien Giang Provincial People's Committee and the Kampot State Administration under the UNEP / GEF project "Prevention of environmental degradation trends in the East Sea and Gulf of Thailand" (Kien Giang PPC, 2003).

$\diamond$ The Fisheries Cooperation Plan between Kampot Fisheries Department and Department of Agriculture and Rural Development of Kien Giang Province, signed on 29/05/2014 (Kien Giang DARD, 2014).

$\diamond$ The agreement on trans-boundary cooperation between An Giang province (Vietnam) and Kandal province (Cambodia) on 6 February 2007. The main content of the search and rescue agreement; exchange of forecast information on storms, floods and warnings; health care; Cooperation in agriculture, fisheries and veterinary (An Giang PPC, 2007).

$\diamond$ The Cooperation Agreement between the Long An Provincial People's Court and the Court of First Instance of Svay Rieng Province - Kingdom of Cambodia dated 31 May 2013. The cooperation agreement between the two provinces includes the following contents: exchange of experi- 
ence of the two parties; information on crime situation, especially drug trafficking, transnational human trafficking and border crossing between Long An and Svay Rieng (Long An PPC, 2013).

$\diamond$ The Cooperation signatures between Dong Thap (Vietnam) and Prieveng (Cambodia). For example, the 2016 cooperation agreement between the two provinces was signed on 10/5/2016. Minutes of cooperation in 2016 include 05 sectors with important contents such as: strengthening the exchange of information between the two provinces to ensure political security and social order in the border area; To create favorable conditions and coordination for the protection of landmarks and positions of demarcated landmarks, stabilizing the entire borderline;...

\subsection{The advantages}

Based on the Memorandums of Understanding (MoU), Agreements or Bilateral Cooperation Plans between two boundary provinces sharing border lines, the sectors of cooperation, dialogue, etc., are diverse and specific from national security and activities on the exchange and sharing convenient information, knowledge and data for their line agencies to set up specific projects and activities in the common border areas. The agreements between two countries have oriented/founded indeed the cooperation and dialogue on the trans-boundary water management for the central organizations (ministries, institutes) and local administration (provinces, departments).

The most highlight cooperation institute is the Mekong Agreement 1995 (1995 agreement) signed by four Low Mekong Basin's (LMB) countries. Vietnam and Cambodia both are very active members and have expressed their concenrs of the water and related development in the Mekong Delta in line with the 1995 agreement. The MRC is the international regional organization established by the 1995 agreement. The 1995 agreement is a dynamic "framework agreement" that enables and requires the MRC to adopt and refine rules and procedures to carry out its work in close cooperation and coordination with relevant agencies and member countries. It identifies key activities and mechanisms that support the sustainable and equitable use, utilization and protection of the Mekong water and water related resources. Under the water utilization procedure (WUP), the MRC and the Member Countries agreed to develop sets of rules for water utilization for the LMB (MRC, 2017).

The Articles 1 and 3 of the 1995 agreement (MRC, 1995) have affirmed the importance of the fields of development the riparian countries benefit from the MRB resources priovided that they have to pursuit the protection of environment as stipulated in Article 3. Besides the Article 1 and 3, the MRC countries can apply the article 7 (prevention and cessation of harmful effects) and 8 (state responsibility for damages) of the Agreement to be able to solve the issues of transboundary Impact caused by the development and management of water resources, especially in the situatuion of emerging development. The example about the effect of MRC's supporting to the bilateral cooperation in LMB is as the below program.

A further joint project, between Cambodia and Vietnam, proposes to promote Communitybased trans-boundary fisheries management in the border areas of the MD, through the fishermen and local governments in the bordering provinces of Prey Veng in Cambodia and Dong Thap in Vietnam contributing to better management and sustainable utilization of fisheries resources through cross-border cooperation. The implementation of joint Neural Information Processing System (NIPS) projects is to occur between 2016-2020 and pending an appropriate funding source. The issue of future development upstream and especially the impact of cascading hydropower projects remains a significant concern to the management of the MD. Climate change and saltwater intrusion also pose significant challenges.

\subsection{The disadvantages}

However, the content of all remain bilateral agreements, MoU or joint plans is general and only orientation for the cooperation and dialogues on the economic, social and security sectors, some elements (sectors) have concerned or been affected by trans-boundary waters (transboundary rivers, main streams) with some central organizations only as the Ministry of Agriculture and Rural development (MARD), the Ministry of Natural Resource and Environment (MONRE). The TWM is indirectly identified or be as independent sector. The exchange or sharing hydro-meteorology, communication information and knowledge related to TWM are not 
touch specially.

In Vietnam, the extensive irrigation systems in the Mekong Delta are used to manage floods for economic benefits and minimize flood impacts, and during the dry season, limit shortages of water for irrigation and prevention (or reclamation) of acid sulphate soils (which is naturally occurring) (Bui, 2017). Therefore, the improvement of existing canal systems is a necessity. The shortage of water also causes salinity intrusion in the main rivers affecting agriculture and living conditions (mostly in Vietnam) will be exacerabated by the impacts of climate change.

The flood control dyke systems built in Vietnam contribute to extensive flooding in the Mekong Delta region of Cambodia and vice versa. Vulnerable provinces in Cambodia include Takeo, Prey Veng and Svay Rieng with flood damage occurring in six out of ten districts in the Takeo province and in Vietnam vulnerable locations along the boundary canals include: Vinh Te canal, Tra Su canal, Bay Xa canal, and Bao Ke canal. The future construction of flood management infrastructure such as road heightening and embankment or water diversion in Cambodia and Vietnam may further increase the water level and prolong the flood period in the flood prone areas in the Mekong Delta. The adverse impacts of flood control infrastructure are discussed and agreed by two sides in many bilateral meetings. But the joint study/research of two countries is still delayed due to the lack of the effective mechanism on the information and data sharing and exchange.

Additionally, there are many raised adverse impacts related to the management of TWM in the boundary region as the trans-boundary water use conflicts, the connection of irrigation canals, the erosion bank at natural boundary line - canals or rivers. And the most of them has been discussed and solved through the establishment of high level, committees and councils, and multilateral agreements where more than 2 countries cover parts of a river basin. For the Mekong River, this includes the establishment of the MRC Council, the MRC Joint Committee and various agreements including the Procedures for Data and Information Exchange and Sharing (PDIES). These are necessary platforms for raising transboundary water sector related issues and setting out regional and national strategies to address them. With membership at the Minister and/or senior executive level, these types of arrangements are generally held no more than 2-3 times per year due to the many other commitments of its members and resources required to bring Ministers and government executive staff together. The less focus has been on establishing the processes to support implementation of transboundary strategies, including monthly, weekly and even day-to-day information sharing and discussions that is often required.

\section{The Proposal CM on TWM between Vietnam and Cambodia for The Mekong Delta}

\subsection{The general characteristics of CM on TWM}

$\mathrm{ACM}$ is considered to be an arrangement for sharing and discussing water resources information between two or more countries to help address trans-boundary issues. It includes, but is not restricted to, high level decision-making committees, technical work groups, emergency response teams, day-to-day storage (dam) operation groups, email groups, forums, workshops and websites. They can be temporary or permanent, focus on addressing one or many issues, and include other characteristics.

Based on the current trans-boundary coordination and cooperation mechanism between Vietnam and Cambodia in MD, the common foundation for the CM on TWM are (Bui, 2017):

- Principle to Develop the CM is some current institutes such as: The Mekong Agreement 1995 and its 5 procedures approved; The existing bilateral cooperation Cambodia - Vietnam is at two levels - central and boundary provincial; The cooperation level is implemented at the basin level and also provincial level.

- Objectives: To promote cooperation between the border provinces of Vietnam and Cambodia in some fields such as: The share and exchange the data and information on water resource and relative issues are required from the boundary provinces of two countries and upper Mekong River Basin; The technical support and capacity building to help the boundary provinces and other stakeholders to address all relative issues on TWM; and The advisory and support decisionmaking of the boundary provincial administrations.

- Scope of CM: The CM is implemented in 
boundary region of MD between two countries; It is established for the boundary provinces of two countries; The CM should focus on the priority main fields (planning, development, assessment and navigation).

- Forum of cooperation: The CM on TWM should include the bilateral and multi-lateral activities of the National Mekong Committees (NMCs), in which, there are Cambodia Mekong Committee and Vietnam Mekong Committee. It means that, the content of CM on TWM takes the Mekong Agreement 1995 with 5 Procedures and Techinal Guilines (Procedure of Water Use Management, Procedure of Data Information Exchange and Sharing, Proceduce for Notification, Prior Communication and Agreement, Procedure of Mitigation Flood Management, Procedure of Water Quality) as its conferences.

The boundary provincial administrations implement some contents of CM on TWM, which should include some main items such as:

- Management: existing border province mechanism Joint meeting (Decision making, Advisory and Resolve conflict). Oversees water resources planning and management processes including river basin planning, flood management planning etc. Generally mid-to-high level groups within government/organization.

- Technique: Provides technical advice to support water resources planning and on-going management, including hydrological, meteorological, engineering, economic and aquatic ecology. Exchanging relevant information and documentation (ex: Flow, Water Quality, ); Exchanging visits of experts and delegations; Joint Study/ research (ex: Fish migration, Bio-diversity, Env. flow...); Joint organizing seminars, workshops and trainings; Capacity building - apply MRC's Decision Support Framework tools for Impact assessment; Joint raising awareness on Flood forecasting.

- Operational: Supports on-going, including day-to-day, water resources management processes including operation of water infrastructure in-line with agree water releases rules and monitoring of water resources. Joint managing the shared water resources and other related natural resources.

- Frequency: This is how often the CM is to meet (if a group) and/or information to be shared (if an online tool). For example, a trans-boundary water resources committee may only need to meet twice a year whereas provincial water depart- ments may need to share information weekly or even daily.

- Membership: Positions and representatives of a CM. For example, a trans-boundary technical working group could comprise of senior hydrologists and hydrogeologists, whereas and a weekly river basin update report could be circulated to a restricted group of government and non-government stakeholders, or even made public via publishing online.

\subsection{Identification of CM on TWM}

A framework is developed to help ensure a systematic and iterative approach to identifying and ensuring close alignment of the CMs to address the joint trans-boundary issues. The example is the first step, which is to identify information and people needs, including skill sets, to support resolution of the trans-boundary issues. Reviews, surveys, meetings and workshops are undertaken by the National Mekong Committees to identify what information is needed, available and accessible, and how best to use it at the trans-boundary level. The assessments of the effectiveness of existing CMs are also undertaken (Figure 1).

\subsection{The proposal CM on TWM}

The mechanism should address all the requirements related to the six joint trans-boundary issues on water management in boundary region of Mekong Delta, which are identified such as table 1 (Bui, 2017).

The flow chart of cooperation mechanism on the trans-boundary water management applied for the boundary provinces in Mekong Delta (Figure 3 ).

The main detail coordination and cooperation mechanism implemented by the boundary provinces of both countries for the Mekong delta are proposed as followings:

- Objectives: To promote cooperation between the boarder provinces of Vietnam and Cambodia in the field such as (1) Exchange information on water resource; (2) Technical Support and capacity building; (3) Advisory and support decisionmaking.

- Areas of Cooperation: Mekong Delta, the boundary provinces are Vietnam's Long An, Dong Thap, An Giang and Kien Giang; Cambodia's Takeo, Prey Veng, Sey Rieng and Kandal. 


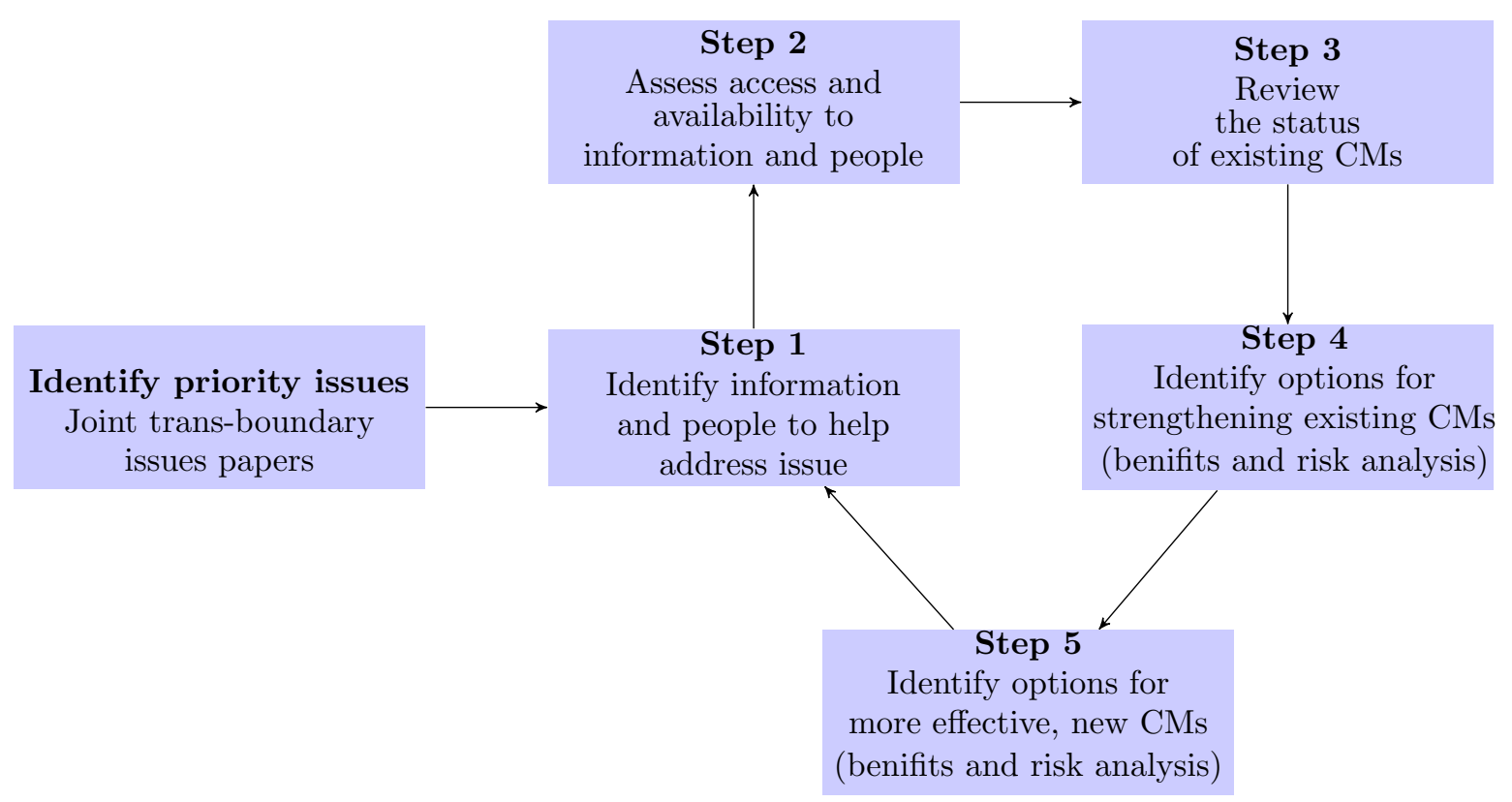

Figure 1. Framework for identifying trans-boundary coordination mechanisms (Bui, 2017).

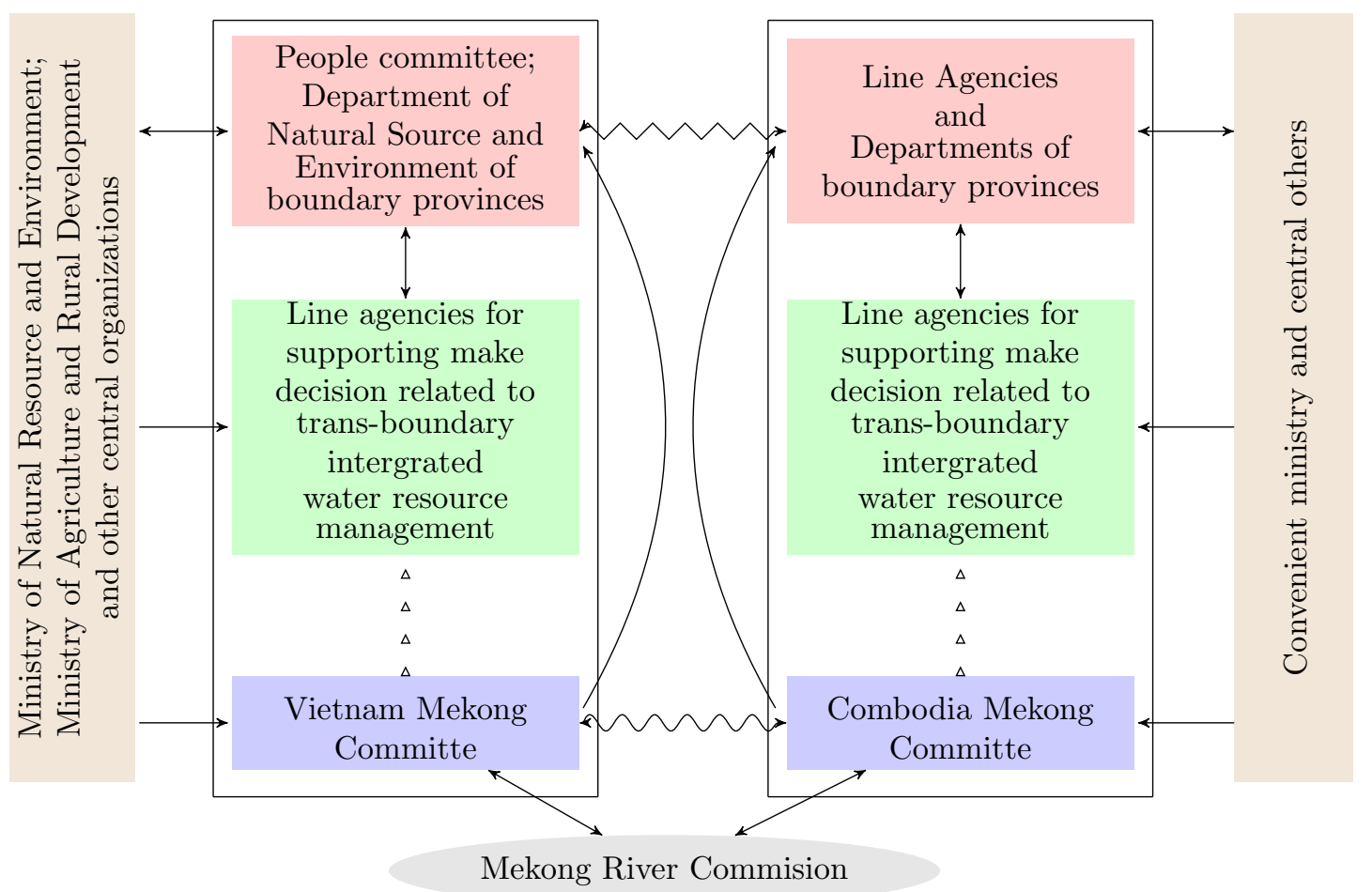

Figure 2. Framework for identifying trans-boundary coordination mechanisms (Bui, 2017).

- Prioritized areas of cooperation: (1) Flood and drought strategic planning; (2) Infrastructure development and investment; (3) Environmental, social and economic impacts of devel- opment and climate change; and (4) The implementation of the Navigation Agreement between Cambodia and Vietnam.

- Form of Cooperation: Exchanging relevant 
Table 1. The content of proposal cooperation mechanism on trans-boundary water management between Vietnam and Cambodia for Mekong Delta

\begin{tabular}{|c|c|}
\hline Elements & Definitions \\
\hline $\begin{array}{l}\text { The addressed } \\
\text { requirements } \\
\text { related to TWM }\end{array}$ & $\begin{array}{l}\text { Make the understanding of hydrological regime. } \\
\text { Make the joint coordination and other convenient activities in the Mekong } \\
\text { Delta. } \\
\text { Make the understanding of environmental, social and economic variances in } \\
\text { boundary region of two countries of Mekong Delta. } \\
\text { Make the agreement or acceptable conditions on the identifying and imple- } \\
\text { menting changes to the flow, water level and hydrological regime necessary. } \\
\text { Make the advantage for the navigation in local river network. } \\
\text { Make the best and advantage condition of canal and river networks in the } \\
\text { border areas. } \\
\text { Implement the measures to address the shortage of water during the dry season } \\
\text { for irrigation, domestic water supply and prevention of salinity intrusion. } \\
\text { Implement the bilateral cooperation. } \\
\text { Implement the consideration trans-boundary implications and impacts of the } \\
\text { infrastructure development and investment related to the water management } \\
\text { sector in boundary region of Mekong Delta. } \\
\text { Implement the support and build the decisions capacity. } \\
\text { Implement the exchange and sharing data, information and knowledge related } \\
\text { to the trans-boundary water management. } \\
\text { Implement the communicating about the flood and drought strategic plan. }\end{array}$ \\
\hline $\begin{array}{l}\text { The data, } \\
\text { information } \\
\text { and knowledge }\end{array}$ & $\begin{array}{l}\text { The convenient data includes: Hydrology of mainstream; Hydrology } \\
\text { of important trans-boundary tributaries; Meteorology data; Geology } \\
\text { data/information; Topography map; Geophysic data/information; Water qual- } \\
\text { ity data/information; and Groundwater data/information;... } \\
\text { The convenient information and knowledge include: Infrastructure information; } \\
\text { Planning information; Water using damage information; Development planning } \\
\text { information; and Social/economic data/information. } \\
\text { The convenient information and knowledge include: Infrastructure information; } \\
\text { Social/economic data/information; and Hazard impacts' information. }\end{array}$ \\
\hline $\begin{array}{c}\text { The special } \\
\text { implement groups }\end{array}$ & $\begin{array}{l}\text { The general management council/group: The group is an active group. } \\
\text { The technical group: The group is a supporting group, which is set up when } \\
\text { has the issue. } \\
\text { The operation group: The group is a supporting group, which is set up when } \\
\text { has the issue or being an active group. The group should implement for the } \\
\text { multiple purposes or many different issues. }\end{array}$ \\
\hline
\end{tabular}

information and documentation on 4 Prioritized areas of cooperation through various means (including, but not restricted to, emails and official channel); Exchanging visits of experts and delegations; Jointly organizing seminars, training workshops and meetings attended by scientists, experts, policy makers, regulators, law enforcers and others concerned; (Capacity building - apply MRC's Decision Support Framework tools for Impact assessment); And developing detailed joint action plans to implement the agreed priority actions.

- Implementation Mechanism: At the national level, it is MRC under the Mekong Agreement 1995. At the provincial level, it is the existing bordering provincial mechanism; And Vietnam Mekong Committee will encourage and facilitate their respective water use organizations, law enforcement agencies, and research institutions, to establish and develop direct contacts and focal points with each other in the field of 4 Prioritized areas of cooperation other related agreements to implement the following tasks: i) develop the annual action plan; ii) monitor and evaluate the implementation of the agreed action plan.

- The boundary provinces' tasks are i) the ap- 
point a coordinator for the purpose of implementing coordination and cooperation mechanism; ii) the implementation of the coordination and cooperation mechanism will be reviewed; iii) the venues and times of coordinators' meetings shall be agreed upon in writing between the coordinators; and iv) each party shall bear its own costs and expenses arising from the implementation of this coordination and cooperation mechanism.

\section{Conclusions and Recommendations}

The establishment of CMs on TWM between Vietnam and Cambodia should be via legislation, international treaties, formal (e.g. Memorandum of understanding) and informal (e.g. handshake) agreements and other arrangements, which are already established and available.

Integrated water resource management program of MRC supports a multi-CMs approach to achieve desired trans-boundary outcomes. All levels of government, and non-government and private sector should be considered in establishing $\mathrm{CMs}$, and approval and on-going resourcing requirements. The proposal CMs between Vietnam and Cambodia should be aligned to support the resolution of priority trans-boundary issues on TWM in MD. This includes consideration of what specific information; people and skill-sets are needed and how often required. Multiple CMs could be required to address one or a number of issues on TWM.

These cooperation mechanisms are based on the current state of the database and new interesting findings may be found as the database continues to expand, as the number and type of actors increases. There is also potential to develop search functions and other features to provide a more 'user-friendly' interface. By doing so, the hope is that through the database contribute to improved coordination, cooperation and learning between two countries working with TWM and provide insights into new opportunities to address knowledge gaps that can lead to more informed decision-making on trans-boundary waters.

\section{References}

An Giang PPC (Provincial People's Committee of An Giang). Agreement dated 6 February, 2007. Agreement on trans-boundary cooperation between An Giang province (Vietnam) and Kandal province (Cambodia).

Bui, H. V. (2017). The national report of the current cooperation and dialogue mechanisms on trans-boundary water management between Vietnam and Cambodia, Mekong Delta Water Management Project. Mekong River Commission.

Bui, H. V. (2015). Initial report on trans-boundary water management between Vietnam and Cambodia, Mekong Delta Water Management Project. Mekong River Commission.

Kien Giang DARD (Kien Giang Department of Agriculture and Development). Agreement dated 29 May, 2014. Aquaculture Development Plan between Kien Giang (VN) and Kampot (Cambodia) provinces.

Kien Giang PPC (Kien Giang Province People Committee). (2003). Agreement dated 27 March, 2003. Agreement on activities at border water region between provinces of Kien Giang and the Kampot State Administration. Under the UNEP/GEF project-prevention of environmental degradation trends in the East Sea and Gulf of Thailand.

Long An PPC (Long An Province People Community). Agreement dated 31 May, 2013. Cooperation Agreement between the Long An Provincial People's Court and the Court of First Instance of Svay Rieng Province - Kingdom of Cambodia.

MRC (Mekong River Commission). (2017). Transboundary water resource management issues in Mekong Delta between Vietnam and Cambodia - Integrated Water Resource Mekong Management Program.

MRC (Mekong River Commission). (1995). Agreement of Mekong Development and Cooperation. 